\title{
Experimental Study on Preparation of Mullite Decorative Materials
}

\author{
J. S. MA ${ }^{1, a}$; M. M. ZHOU ${ }^{1, b,} ;$ H. Q. CAi ${ }^{1, c} ;$ R. S. BAI ${ }^{1, d}$ \\ ${ }^{1}$ Department of Civil Engineering, Hebei University of Architecture, Zhangjiakou 075000, China \\ ahbmjs@163.com, 'bhoumiaomiao345@163.com, ${ }^{\mathrm{C}} \mathrm{zjk}$ kchq@163.com, ${ }^{\mathrm{d}}$ shsbrsh@163.com
}

Keywords: Mullite, Decorative materials, Preparation

\begin{abstract}
The pouring vibration method is adopted to prepare a fireproof, durable and decorative wall panel, whose materials for preparation are mullite, cement, powder, glass beads, cellulose, pigments and waterproofing agent. The test result shows that the greatest dosage of raw materials for preparing decorative plates is mullite : cement : glass beads : powder : cellulose : pigment : waterproofing agent $=100: 60: 20: 5: 1: 10: 5$. Under the ratio, the decorative wall panel gained the apparent density of $942 \mathrm{~kg} / \mathrm{m}^{3}$, compressive strength of $7.6 \mathrm{MPa}$, flexural strength of $2.3 \mathrm{MPa}$ and water absorption of $6.5 \%$.
\end{abstract}

\section{Introduction}

With the development of structure decorative integration board and prefabricated buildings, it is very important to develop new wall decoration materials. The external finish materials are aluminum panels, decorative stone, glass walls, decorative bricks, exterior house paint, etc. in China ${ }^{[1]}$. Aluminum plate has the disadvantage of being non-fireproof. Dry hanging stone is tedious for construction process and heavy in weight. Glass curtain wall will cause light pollution and is easy to break. As the decorative brick, there are some security risks such as falling off the surface of the wall after a long time. The durability of exterior house paint is not good, which is easy to crack from the skin. At this stage, there are many problems in decorative materials. On the one hand, many decorative materials are combined with organic insulation materials which are not fire-resistant, thus fire occurs suddenly in the building. On the other hand, most decorative materials are short-lived. The key issue to be resolved is to make sure those structural materials and decorative materials are in the same lifetime and decorative materials have good fire performance. Considering the conditions of decoration materials, we need to pay attention to a more outstanding fireproof, well decorative and more durable decorative material.

Mullite is an aluminum silicate mineral, with high refractoriness, thermal shock resistance, and chemical resistance, and creep resistance, high load softening temperature, good volume stability, electrical insulation and other properties. Mullite, which is widely used in metallurgy, glass, ceramics, chemistry, power, national defense, gas and cement industries, is ideal for senior refractory materials ${ }^{[2]}$. The main mullite products are mullite bricks, mullite insulation tiles and mullite fiber in China. Mullite has good fire resistance and high strength which is suitable to use as decorative materials. In the study, these materials of mullite, cement, glass beads, powder, and cellulose are mixed to prepare a new exterior wall decorative plate and its performances of strength and apparent density are analysed at last.

\section{Experimental Materials}

\section{Mullite}

Mullite powder is in 200 meshes produced by Zhengzhou Xiangyu Casting Material Co., Ltd. Performance test results are shown in table 1. 
Table 1 Results of mullite performance.

\begin{tabular}{lllll}
\hline Items & $\begin{array}{l}\text { Main phase of } \\
\text { mullite }(\%)\end{array}$ & $\begin{array}{l}\text { efractoriness } \\
\left({ }^{\circ} \mathrm{C}\right)\end{array}$ & $\begin{array}{l}\text { Bulk density } \\
\left(\mathrm{g} \mathrm{cm}^{-3}\right)\end{array}$ & $\begin{array}{l}\text { Loss on } \\
\text { ignition }(\%)\end{array}$ \\
\hline Specification & $\geq 60$ & $\geq 1770$ & $>2.5$ & $<0.25$ \\
\hline
\end{tabular}

\section{Glass Beads}

Expanded glass beads are produced by Beijing-energy Industrial Technology Development Co., Ltd. which are irregular spherical particles with a particle size of $0.5-2 \mathrm{~mm}$, glassy and closed of the surface. Performance test results are shown in table 2.

Table 2 Test results of glass beads performance.

\begin{tabular}{llll}
\hline $\begin{array}{l}\text { Physical } \\
\text { properties }\end{array}$ & $\begin{array}{l}\text { Bulk density } \\
\left(\mathrm{kgm}^{-3}\right)\end{array}$ & $\begin{array}{l}\text { Cylinder compressive } \\
\text { strength(KPa) }\end{array}$ & $\begin{array}{l}\text { Thermal conductivity } \\
\left(\mathrm{W}(\mathrm{m} \cdot \mathrm{k})^{-1}\right)\end{array}$ \\
\hline Test results & 100 & 156 & 0.047 \\
\hline $\begin{array}{l}\text { Physical } \\
\text { properties }\end{array}$ & $\begin{array}{l}\text { Water } \\
\text { absorption (\%) }\end{array}$ & Floating ratio (\%) & $\begin{array}{l}\text { Vitrified and closed ratio of } \\
\text { the surface }(\%)\end{array}$ \\
\hline Test results & 42 & 92 & 87 \\
\hline
\end{tabular}

Cement

42.5\# Portland cement is chosen which is produced by Xuanhua Jinyu Cement Plant.

\section{Powder}

Latex powder SP1026 is starch ethers which is produced by Wellcome Industry Company in Henan.

Cellulose

Carboxymethyl cellulose HL8 in the experiment is produced by Wellcome Industry Company in Henan.

\section{Pigment}

Iron oxide pigments are selected in the experiment which is produced by Tianjin Middle Honghua Chemical Co., Ltd.

\section{Waterproofing Agent}

Methyl-sodium waterproofing agent in the experiment is produced by Foshan GHK Silicone Material Co., Ltd.

\section{Experimental Method}

It puts mullite as the main decorative material, cement and powder as adhesive, a small amount of glass beads as aggregates, at the same time adds a proper amount of cellulose, pigments, and the right amount of waterproofing agent by the method of pouring and vibrating molding for preparing mullite decorative panels. According to the table 4, the raw materials are accurately weighed and uniformly mixed and then pigments and water are added and well stirred. The content of each material is expressed by the mass percentage of mullite, where the powder, pigment and water are fixed at $5 \mathrm{wt}-\%, 10 \mathrm{wt}-\%, 100 \mathrm{wt}-\%$. The experiment gained the optimal dosage and main factors of raw materials affecting the decorative panels. Compressive strength of decorative materials is tested by WYA-600 electro-hydraulic pressure testing machine and flexural strength by DKZ-5000 electric bending testing machine. Water absorption ratio test is performed by the group 15 in table 3 . In accordance with table 4, hydrophobic of decorative materials by different contents of water repellent is gained and the optimal dosage waterproofing agent is determined. 
Table 3 Testing ratio of mullite decorative materials

\begin{tabular}{lllll}
\hline Group & Mullite (\%) & Cement (\%) & Glass beads (\%) & Cellulose (\%) \\
\hline 1 & 100 & 30 & 10 & 0.6 \\
\hline 2 & 100 & 45 & 10 & 0.6 \\
\hline 3 & 100 & 60 & 10 & 0.6 \\
\hline 4 & 100 & 75 & 10 & 0.6 \\
\hline 5 & 100 & 90 & 10 & 0.6 \\
\hline 6 & 100 & 60 & 15 & 0.6 \\
\hline 7 & 100 & 60 & 20 & 0.6 \\
\hline 8 & 100 & 60 & 25 & 0.6 \\
\hline 10 & 100 & 60 & 30 & 0.6 \\
\hline 11 & 100 & 60 & 20 & 0.6 \\
\hline 12 & 100 & 60 & 20 & 0.6 \\
\hline 13 & 100 & 60 & 20 & 0.6 \\
\hline 14 & 100 & 60 & 20 & 0.6 \\
\hline 15 & 100 & 60 & 20 & 0.8 \\
\hline 16 & 100 & 60 & 20 & 1.0 \\
\hline
\end{tabular}

Table 4 Water absorption of mullite decorative materials

\begin{tabular}{llllll}
\hline Waterproofing agent content (\%) & 2 & 3 & 5 & 8 & 12 \\
\hline Water absorption (\%) & 9.0 & 7.0 & 6.5 & 6.2 & 6.0 \\
\hline
\end{tabular}

\section{Experiments}

\section{The Preparation of Mullite Decorative Materials}

Different from the existing molding process of plates, the technology of directly pouring vibrating molding is applied to make mullite decoration materials. In the molding process, it is important to control the castable consistency, trying to make molding at a small extra vibration. It is easy and convenient to run the whole process in the experiment.

As can be seen from Fig.1, the preparation process for mullite decoration materials is shown as follows. The first step is mixing with cement, mullite, glass beads, powder, cellulose, and pigments, dry stirring for 1 to 2 minutes. Then add a certain amount of water in the mixture and stir for 3 to 5 minutes to get wet mixture. The wet mixture is then poured into the mold which is brushed with a release agent in the dimension of $150 \mathrm{~mm} \times 150 \mathrm{~mm} \times 10 \mathrm{~mm}$. After pouring vibrated molding, the panel should be cured covering with a thin plastic film on the side surface of the mold for two days at natural temperature. Finally, release the test block from the mold and spray waterproofing agent in decorative plate surface and then be in natural conservation for a week (The water repellent is brushed or sprayed in the decorative surface of plate which is dilluted for 10 to 15 times with rags, sponges, brushes, rollers and sprayers. Before brushing or spraying the second time, the surface must be dry). 


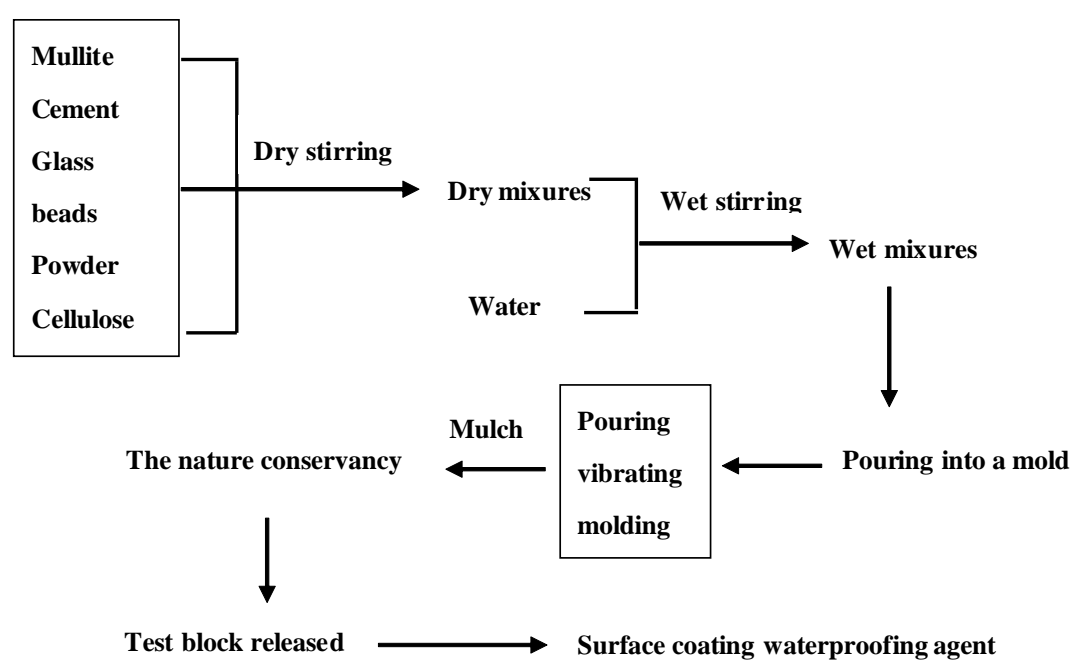

Figure 1 The technical process of preparation for mullite decorative materials.

\section{Results and Discussion}

\section{Effects of Dosage of Cement on Mullite Decorative Materials}

It is seen from Fig. 2 and Fig. 3, strength of the sample increases with the increase of cement, but the growth rate of flexural strength is small. The more dosage of cement adds, the more cement hydration products get, which can be firmly bonded with aggregates and play a better role of the supporting skeleton, significantly increasing the compressive strength of the sample. However, water absorption of the sample also increases if adding too much cement into the mixture. While the apparent density of the sample decreases by adding cement. This is due to the high density and great strength of mullite. Considering the effect of cement content on the strength and density of the sample, the best cement content of $60 \%$ is selected.

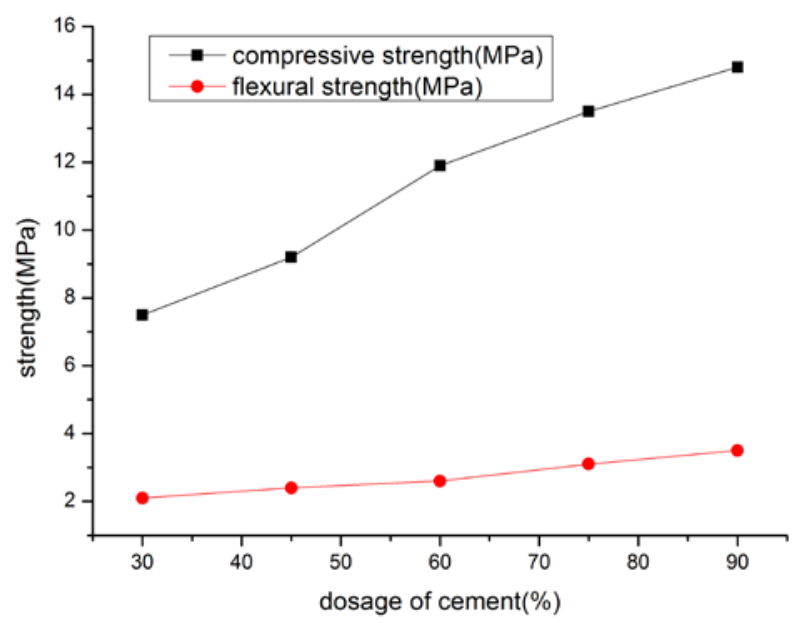

Figure 2 Effects of dosage of cement on the strength of the sample. 


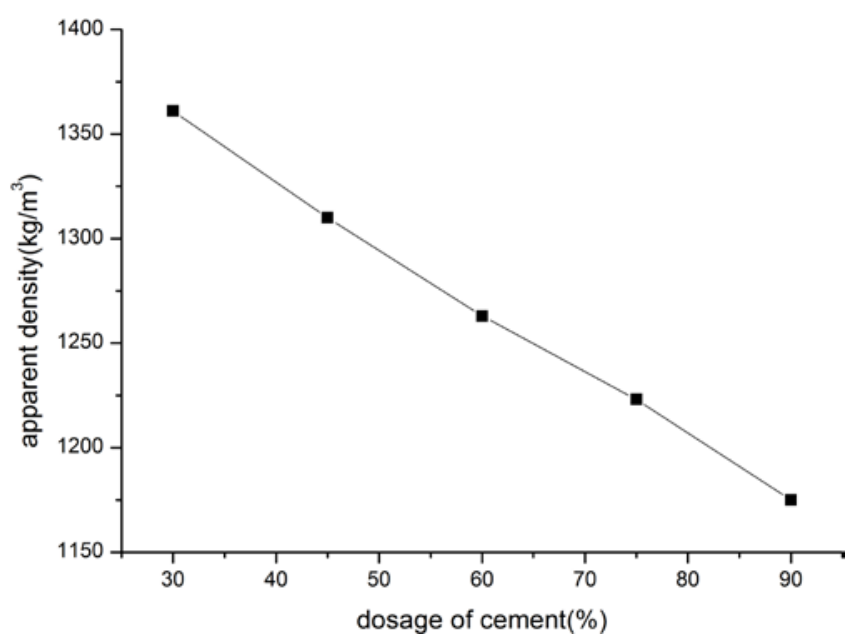

Figure 3 Effects of dosage of cement on the apparent density of the sample.

\section{Effects of Dosage of Glass Beads on Mullite Decorative Materials}

Fig. 4 and Fig. 5 indicate that the strength and apparent density of the sample with glass beads are small. The rate of decline of the strength and apparent density is larger when the glass beads mixing amount is less than $20 \%$. When the glass beads mixing amount reaches $20 \%$, the apparent density of the sample reduced to about $930 \mathrm{~kg} / \mathrm{m}^{3}$.The main reason is that glass beads has a much smaller strength and apparent density than other decorative materials. As coarse aggregates of decorative materials, glass beads have played the role of preventing cracking of plates.

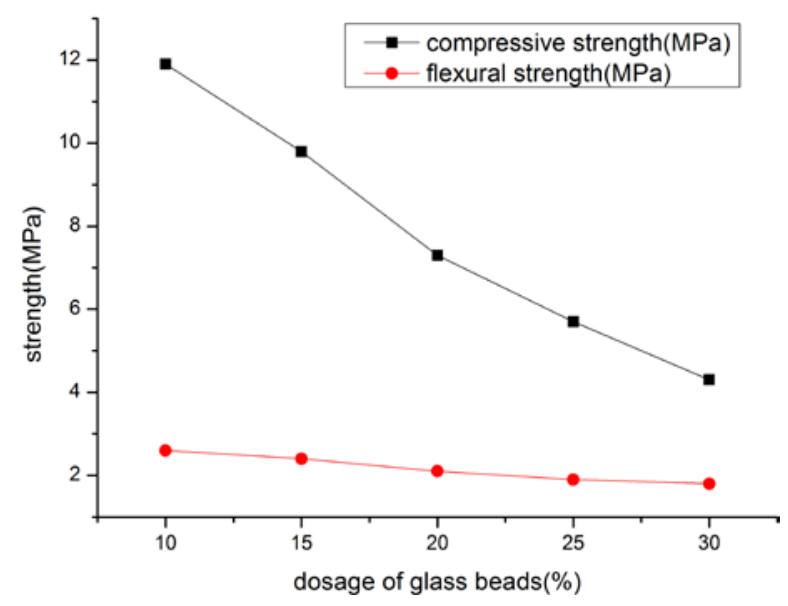

Figure 4 Effects of dosage of glass beads on the strength of the sample.

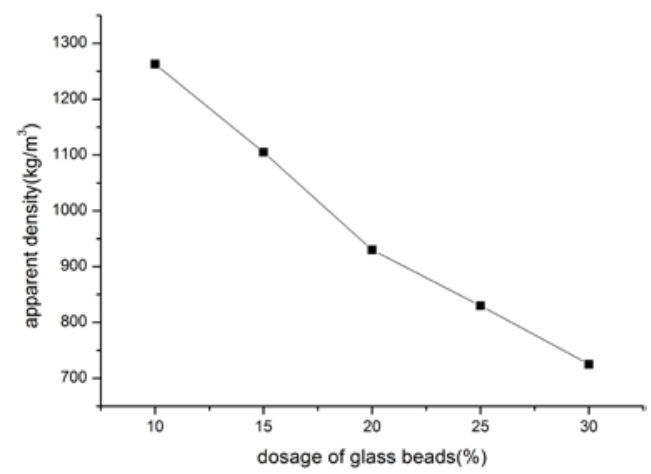

Figure 5 Effects of dosage of glass beads on the apparent density of the sample. 


\section{Effects of Dosage of Cellulose on Mullite Decorative Materials}

As is shown in Fig. 6, the compressive strength of the specimen shows a downward trend with the increasing content of cellulose, but the decline is very small. And there is little variety in flexural strength. Since cellulose has a cohesive effect and water retention, it improves the workability of decorative materials, reducing the amount of water. Considering the effect of cellulose dosage on the strength of the sample, the best content of cellulose is $1 \%$.

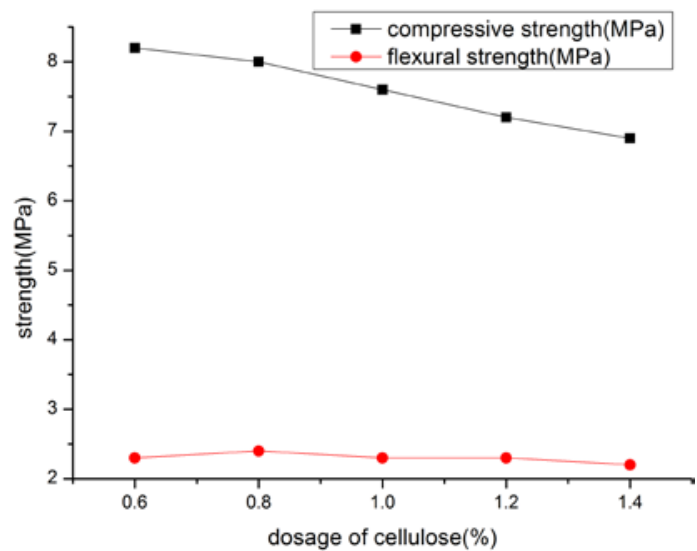

Figure 6 Effects of dosage of cellulose on the strength of the sample.

\section{Effects of Dosage of Waterproofing Agent on Mullite Decorative Materials}

As is shown in table 5 , when the waterproofing agent content is $5 \%$, water absorption of the sample is $6.5 \%$, which can be better to improve the waterproof performance. The decline of water absorption is not obvious when increasing the dosage of waterproofing agent. So the best waterproofing agent content is $5 \%$.

\section{Conclusions}

The optimum proportion of decorative materials is mullite : cement : glass beads : powder : cellulose : pigment : waterproofing agent $=100: 60: 20: 5: 1: 10: 5$. The test result of the decorative materials is with compressive strength of $7.6 \mathrm{MPa}$, bending strength of $2.3 \mathrm{MPa}$, an apparent density of $942 \mathrm{~kg} \mathrm{/} \mathrm{m}^{3}$, the water absorption of $6.5 \%$.

The external decorative plates are prepared by the method of pouring vibration molding whose preparation process is simple. The decorative plates are suitable for mass production in precast plants.

\section{Acknowledgement}

This research was financially supported by the National Science Foundation of Hebei province (E2012404004).

\section{References}

[1] Y. P. Lei, P. H. Dang \& G. Zhou, Application status and development direction of building exterior finish materials. Modern Coating Technologies, 3, pp. 16-18, 2004.(In Chinese)

[2] D. Chen \& N. C. Chen, Research progress of mullite. Mineral Resources and Geology, 18(1), pp. 52-54, 2004. (In Chinese) 